\title{
Haematemesis from a coronary artery caused by penetration of a gastric ulcer in a hiatus hernia
}

\author{
H. R. Matthews \\ From the Cardio-thoracic Surgical Centre, Broadgreen Hospital, Liverpool
}

$A$ case is described in which the left ventricular myocardium was penetrated by a gastric ulcer located in a hiatus hernia. Haemorrhage occurred from a branch of the left circumflex coronary artery and was eventually fatal. The situations in which the heart can be involved by peptic ulceration are reviewed.

Penetration of the heart by a gastric ulcer is a rare event, even if the stomach has come to lie in the thorax by virtue of a diaphragmatic hernia. Discussing the location of peptic ulcers in hiatal herniae, Macarthur and Wright (1969) comment that though ulceration on the lesser curve at hiatal level might be the commonest situation, any site is possible and may result in perforation into any related organ. This report describes the features and treatment of a case in which a gastric ulcer in a hiatus hernia penetrated the left ventricular myocardium with severe haemorrhage from erosion of a branch of the left coronary artery.

\section{Case report}

The patient, a housewife aged 7I, had suffered dyspeptic symptoms for over 20 years and in 1967 had sustained a perforated duodenal ulcer requiring emergency surgical closure. In December 1972 she had developed pneumonia which was treated in hospital. From the time of discharge she continued to take bendrofluazide, theophylline, bisacodyl, and nitrazepam. On 3 February 1973 she was admitted as an emergency to a local hospital, having vomited an estimated $150 \mathrm{ml}$ of blood during the previous night. This was not accompanied by pain and there had been no previous haematemesis, but there was a history suggestive of melaena and she reported weight loss of approximately $25 \mathrm{~kg}$ over the preceding two years. There was no history of ingestion of aspirin or alcohol.

On examination she was sweating but apyrexial. The pulse was irregular, 136/min and the blood pressure $115 / 85 \mathrm{mmHg}$. There was no oedema or increase in jugular venous pressure, but crepitations were present at both lung bases. Abdominal examination revealed only pronounced obesity and an upper midline incisional hernia $25 \mathrm{~cm}$ in diameter which was not tender. Rectal examination revealed altered blood. Investigations showed: Hb II.I g/100 ml, mean corpuscular haemoglobin concentration 30 per cent, serum sodium 136 $\mathrm{mEq} / \mathrm{l}$., serum potassium 6.1 mEq/l., blood sugar 142 $\mathrm{mg} / \mathrm{r} 00 \mathrm{ml}$, and blood urea $130 \mathrm{mg} / 100 \mathrm{ml}$. The electrocardiogram showed generalized ischaemic changes and atrial ectopic beats with intermittent left bundle-branch block. The chest $x$-ray showed blurring of the whole of the cardiac outline, with the possibility of a mass adjacent to the right border of the heart.

Haemorrhage from a hiatus hernia or duodenal ulcer was the initial diagnosis. Blood transfusion was started and a nasogastric tube passed. Digitalis and frusemide were given. On the next morning a further haematemesis occurred, however, and the blood pressure dropped to $95 / 60 \mathrm{mmHg}$. Endoscopy was not performed but a barium meal showed a massive hiatus hernia with a large filling defect within it and obstruction to the passage of barium into the abdomen. A diagnosis of volvulus or carcinoma of the stomach associated with a hiatus hernia was considered and the patient transferred to Broadgreen Hospital for surgical treatment.

Operation was performed the same day. The chest was entered through a left thoraco-abdominal incision revealing a hiatus hernia $13 \mathrm{~cm}$ in diameter which was adherent to the lung and pericardium. On mobilizing the hernia from the pericardium an ulcer crater, $6 \times 3 \mathrm{~cm}$, was opened between the stomach and the left ventricular myocardium. The ulcer floor consisted of eroded myocardium covered by friable granulation tissue with brisk bleeding from a branch of the left circumflex coronary artery into the gastric lumen which contained $400 \mathrm{ml}$ clotted blood. The pericardium was completely absent over the area of ulceration but at the margins was densely adherent to the left ventricle and there was no free communication with the pericardial cavity. Attempts to suture the bleeding vessel were not successful as the 
granulation tissue would not hold sutures even when reinforced with 'teflon' felt, but haemostasis was eventually achieved by suturing the tough pericardial edges together over the ulcer and effectively plicating it. The gastric ulcer occupied nearly the whole of the lesser curve and three-quarters of the stomach had to be resected. Mobilization of the gastric remnant was complicated by adhesions from the previous operation but alimentary continuity was finally restored by end-to-end oesophagogastric anastomosis just below the aortic arch.

Postoperatively the patient was fully conscious but required elective positive-pressure ventilation, and tracheotomy was performed on 5 February. On 7 February ventricular fibrillation occurred.

Successful resuscitation by external massage and DC defibrillation was followed by extensive surgical emphysema. Cardiac arrhythmias, including atrial, nodal, and ventricular tachycardias, continued and finally resulted in death on 9 February.

At necropsy the suture line over the eroded myocardium was intact with no evidence of postoperative haemorrhage. On transverse section the ulcer that was visible on the surface of the heart had penetrated to within $0.5 \mathrm{~cm}$ of the left ventricular cavity (Fig.). There was generalized myocardial fibrosis and moderate coronary atheroma. The lungs were congested with basal collapse and infection. Histology of the ulcer in the myocardium and stomach showed chronic benign peptic ulceration.

\section{Discussion}

Although extremely rare, penetration of the heart by peptic ulceration can occur in three main ways.

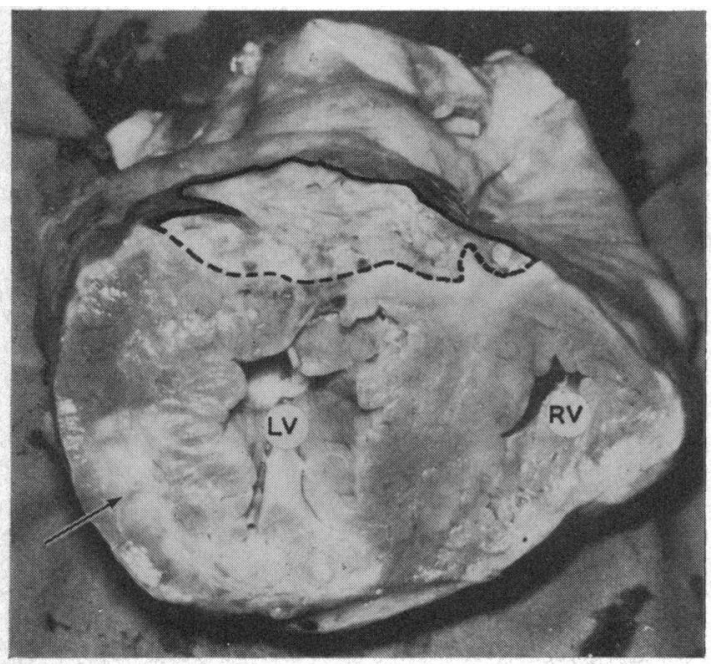

FIG. Transverse section of the ventricles at necropsy. The posterior surface of the heart is upwards. The base of the ulcer is indicated by the dotted line. The arrow indicates myocardial fibrosis from previous infarction; $L V$ - left ventricle; $R V$ - right ventricle.
The first is by extension through the diaphragm of a gastric ulcer in a normally placed stomach. Prolla, Taebel, and Kirsner (1967) were able to find 7 such cases in a review of the world literature. Secondly, it may occur by direct extension of a gastric ulcer located in a diaphragmatic hernia, of whatever type. Such ulcers have been known to penetrate the pericardium (Frey, 1961), aorta (Macarthur and Wright, 1969), lung (Effler and Ballinger, 1951), and pleura (Ochsner and Ochsner, 1958). The heart itself has been involved on at least one occasion with fatal haemorrhage from the pulmonary artery (Schaper, 1926). Thirdly, peptic ulcers in organs other than the stomach may involve the heart. Itabashi and Granada (1972) described perforation of the left atrium by a peptic ulcer of the oesophagus, with recurrent cerebral food embolism and fatal haemorrhage, and Prolla et al. (1967) reported perforation of the same chamber by an anastomotic ulcer after oesophagogastrectomy for benign oesophageal stricture.

On this evidence the case described here, though possibly unique, is not entirely unexpected. Whether hyperacidity was a factor in the production or extension of the ulcer is unknown. It is notable that 2 of the 5 cases of penetrating gastric ulcer in a hiatus hernia reported by Macarthur and Wright (1969) also had indisputable duodenal ulceration at some time in their course, as in this case.

The surgical technique employed appears to have been effective in controlling the acute haemorrhage, though survival was admittedly short. Death was caused by cardiac arrhythmias but it is not clear whether these resulted from the pre-existing ischaemic heart disease or from inflammation and destruction of the myocardium by the advancing ulcer. If the patient had not bled from a coronary artery presumably the next event would have been perforation of the left ventricular cavity.

The possibility of major vascular involvement by a peptic ulcer has therefore to be considered in any patient with alimentary haemorrhage and a hiatus hernia. The anticipation of such a situation may minimize technical difficulties at operation and contribute to a more favourable outcome than in this instance.

\section{References}

Effler, D. B., and Ballinger, C. S. (1951). Complications and surgical treatment of hiatus hernia and short esophagus. Fournal of Thoracic Surgery, 22, 235.

Frey, E. (196I). Perforation eines Magenulkus aus einer Hiatushernie ins Perikard. Fortschritte auf dem Gebiete der Röntgenstrahlen und der Nuklearmedizin, 95, 852.

Itabashi, H. H., and Granada, L. O. (I972). Cerebral food embolism secondary to esophageal-cardiac perforation. fournal of the American Medical Association, 219, 373. 
Macarthur, A. M., and Wright, J. E. C. (1969). Complications of intrathoracic gastric ulcer associated with hiatus hernia. British Fournal of Surgery, 56, 161.

Ochsner, S. F., and Ochsner, A. (1958). Hiatal hernia with gastric occlusion and intrathoracic perforation of gastric ulcer on the greater curvature. American fournal of Surgery, 96, 562.

Prolla, J. C., Taebel, D. W., and Kirsner, J. B. (1967). Perforation of an esophagogastric anastomotic ulcer into the left atrium. Gastroenterology, 52, $87 \mathrm{r}$.
Schaper, K. (1926). Chronisches Magenulcus mit Arrosion eines Astes der Arteria pulmonalis bei transdiaphragmatischem Magenprolaps nach Brustzwerchfellschuss. Deutsche Zeitschrift für Chirurgie, 194, 169.

Requests for reprints to H. R. Matthews, Esq., F.R.C.S., Cardio-thoracic Surgical Centre, Broadgreen Hospital, Thomas Drive, Liverpool Lr4 3LB. 